ARMS.72 6.2

Distribution Caregory UC-41

\title{
Aerial Radiological Measuring Surveys of the Turkey Point Station April 1972
}

EG\&G. Inc. Las Vegas, Nevada

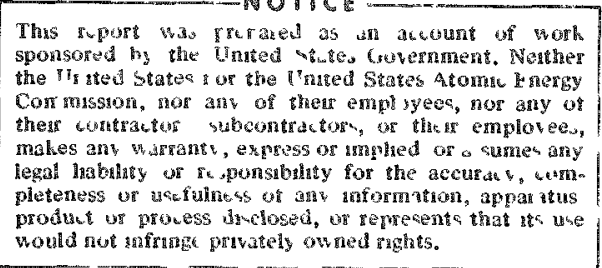

This reporf is part of a series on the combnung acpivites of the Acrial Radiological Measurng System operated for the U. S. Atomuc Energy Commission. The ARMS pragran is inanaged by the Division of Operaiconal Satery and is a cooperative offorit mong various offices ond divisions of the Commission. 


\section{DISCLAIMER}

This report was prepared as an account of work sponsored by an agency of the United States Government. Neither the United States Government nor any agency Thereof, nor any of their employees, makes any warranty, express or implied, or assumes any legal liability or responsibility for the accuracy, completeness, or usefulness of any information, apparatus, product, or process disclosed, or represents that its use would not infringe privately owned rights. Reference herein to any specific commercial product, process, or service by trade name, trademark, manufacturer, or otherwise does not necessarily constitute or imply its endorsement, recommendation, or favoring by the United States Government or any agency thereof. The views and opinions of authors expressed herein do not necessarily state or reflect those of the United States Government or any agency thereof. 


\section{DISCLAIMER}

Portions of this document may be illegible in electronic image products. Images are produced from the best available original document. 


\begin{abstract}
The Aerial Radiological Measuring System (ARIMS) was used to survey the area surrounding the Turkey Point nuclear power station during April 1972, prior to reactor start-up. The survey measured terrestrial background gamma radiation.

A high-sensitivity detection system collected gamma-ray spectral and gross-count data. The data were then computer processed into a map of a 175 square mile area showing isoexposure contours three feet above the ground. Exposure rates and isotopes identified are consistent with normal terrestrial background radiation.
\end{abstract}




\section{ACKNOWLEDGMENTS}

Special appreciation is given to L. J. Deal (Assistant Director, DOS/Health Protection, USAEC) for his support and encouragement in this program. 
CONTENTS

1. INTRODUCTION. . . . . . . . . . 1

1. 1 Identification of Surveyed Plant and Area . . 1

1.2 ARMS Program . . . . . . . . 1

1.3 ARMS Equipment and Procedures . . . . 1

1.4 Reduction and Presentation of Data . . . . 4

2. REACTOR AND SITE CHARACTERISTICS . . . . 5

2.1 Reactor Characteristics . . . . . . 5

2.2 Site Area Characteristics . . . . . 6

3. SURVEY PLAN • . . . . . . . . . 8

3.1 Specification of Flight Lines . . . . . 8

3.2 Coordination with Local Authorities. . . . 8

4. RADIOLOGICAL SURVEY • • 。 。 • 。 . 9

4.1 Survey Missions . . . . . . . . 9

4.2 Gross-Count Data. . . . . . . . . 99

4.3 Spectral Data. . . . . . . . . 11

5. SUMMARY AND CONCLUSIONS . . • . . . 14 


\section{INTRODUCTION}

1.1 Identification of Surveyed Plant and Area

The Aerial Radiological Measuring System (ARMS)

(Ref. 1) operated by EG\&G, Inc., Las Vegas, Nevada, for the U. S. Atomic Energy Commission was used to perform a gamma radiation survey of an extensive area surrounding the Turkey Point nuclear power station during April 1972, prior to reactor start-up. The Turkey Point Station, operated by the Florida Power and Light Company, is located at Turkey Point, Florida. The size of the survey area was 175 square miles.

1.2 ARMS Program

The present survey was made as part of a continuing nationwide ARMS program started in 1958 to monitor radiation levels surrounding facilities producing or utilizing radioactive materials. This is the first such survey performed in the Turkey Point area.

The detection system on board the aircraft collects gamma-ray gross-count and spectral data on each flight line of the suriey. The gamma radiation and aircraft position information are processed by a computer into an isoexposure contour map of the area surveyed.

1.3

ARIMS Equipment and Procedures

The ARMIS aircraft and its on-board radiation detection equipment were used in the survey. Since the ARIMS equipment and procedures have been discussed in detail elsewhere (Ref. 1), they will only be described briefly here.

The ARMS surveys are flown in a Beechcraft Twin Bonanza at an altitude of 300 to 500 feet above terrain at a ground speed of about $140 \mathrm{knots}(235 \mathrm{ft} / \mathrm{sec})$. The ground position of the aircraft and its altitude above terrain are measured and recorded every other second by a radar navigation computer system. The position and altitude measurements are accurate to $\$ 350 \mathrm{ft}$ and $\pm 5 \mathrm{ft}$, respectively. 
A typical flight pattern consists of a series of parallel lines spaced one nautical mile (6080 feet) apart, covering all of the land area within a twelve and one-half nautical mile radius of the facility.

At an altitude of 500 feet, the field of view of the detectors is approximately $1 / 4$ mile wide for a mean gamma energy of naturally occurring isotopes.

The aerial radiation measurements are of two distinct types, made simultaneously: (1) gross gamma count (intensity) measurements and (2) gamma spectral measurements. The detector system consists of an array of fourteen $4 \times 4$ in. NaI $(T h)$ scintillation crystals, each coupled to its own photomultiplier assembly. The detector system output is directed both to the gross gamma count computing system and to the multichannel spectrum analyzer. The data collecting system is shown in Figure 1.

The gross gamma count system consists of an amplifier-discriminator-computer unit that counts and records the total number of gamma-rays of energy greater than $50 \mathrm{keV}$ that are detected during a 1-second time interial. The gross gamma count rate (number of gamma-rays detected per second) is digitally recorded along with aircraft position and altitude every other second. Aircraft position data are supplied by a track navigational computer and doppler radar. Altitude above terrain is measured with a radar altimeter. As a backup and complement to the digital recording of the grosscount data, a record is made on a continuous strip chart of both gross gamma count rate and radar altitude as a function of distance. Typical gross-count rates for natural background are several thousand per second.

Whereas the gross gamma count data specify the intensity of radiation as a function of position, the gamma spectral data are useful in identifying particular radioactive isotopes. A pulse-height analyzer automatically sorts detected gamma-rays according to energy, the reby generating a number per unit-energy versus energy spectrum. Although gamma rays occur only at well known discrete energies characteristic of the emitting species, air 


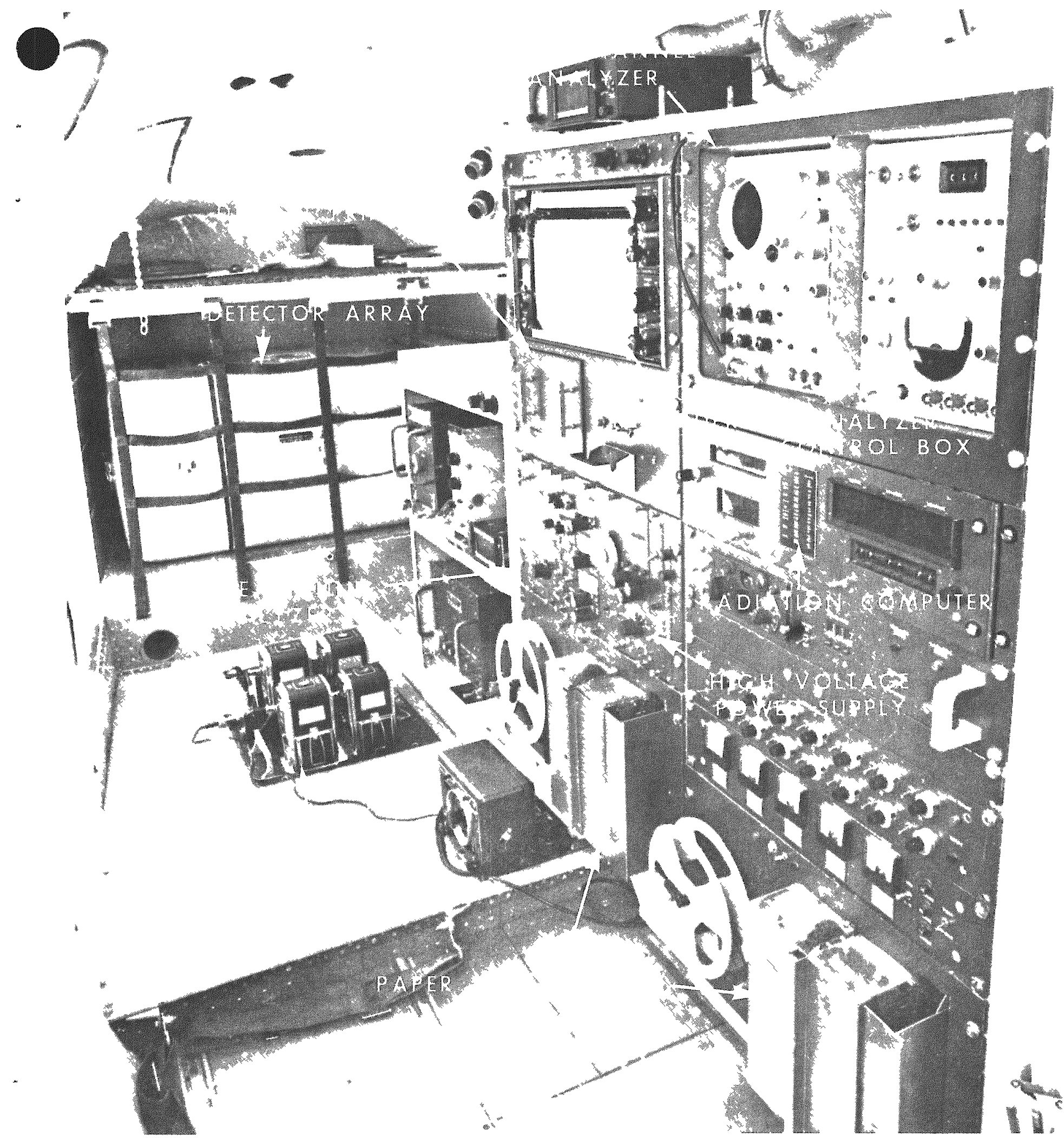

FIGURE 1. View of the interior of the Aexial Radiological Measuring (ARMS) aircraft showing detector package and electronic data collection system. 
scattering tends to smear the detected distribution. Nevertheless, the characteristic peaks that permit isotope identification are readily observable. In wide area surveys the typical acquisition time for a gamma-ray spectrum is several minutes; thus the spectrum represents the average radiological properties of a tract several miles in length. However, if an area of interest is indicated by an increase in the gross gamma count rate, spectral data acquisition times of only a few seconds are used to isolate the area spatially. If further investigation is warranted, a ground mobile unit with equipment similar to that in the aircraft is available to provide greater spatial and energy resolution.

In addition to the equipment just described, the ARMS aireraft also carries an air sampling and analysis system for the measurement of airborne radioactivity.

1.4 Reduction and Presentation of Data

The raw data from the gross gamma count and the gamma spectral measurements are permanently recorded on paper tape, which is computer processed and analyzed to characterize the radiological proparties of the area surveyed. Using an altitudedependent conversion factor obtained from prior calibration measurements, the raw gross-count rate is converted to exposure rate $(\mu \mathrm{R} / \mathrm{hr})$ at three feet above ground.

The exposure rate conversion factor was obtained from repeated flights 200 to 1000 feet above terrain containing known distributions of natural isotopes. Such conversion factors have proved valid over distributed fission product fields, with a variation of less than $25 \%$. In practice, variations of $2 \mu \mathrm{R} / \mathrm{hr}$ or greater can be reliably obselved in repeated llights over the same area. 


\section{REACTOR AND SITE CHARACTERISTICS}

\section{$2.1 \quad$ Reactor Characteristics}

The Turkey Point Reactor is located in Dade County, Florida, 26 miles south of Miami.

The principal nuclear contractor is the Westinghouse Electric Corporation. The facility is oparated by the Florida Power and Light Company.

Table 1 gives the specifications of the reactor facility. At the time of the survey the reactor had not yet commenced operating.

TABLE 1. Reactor facility specifications.

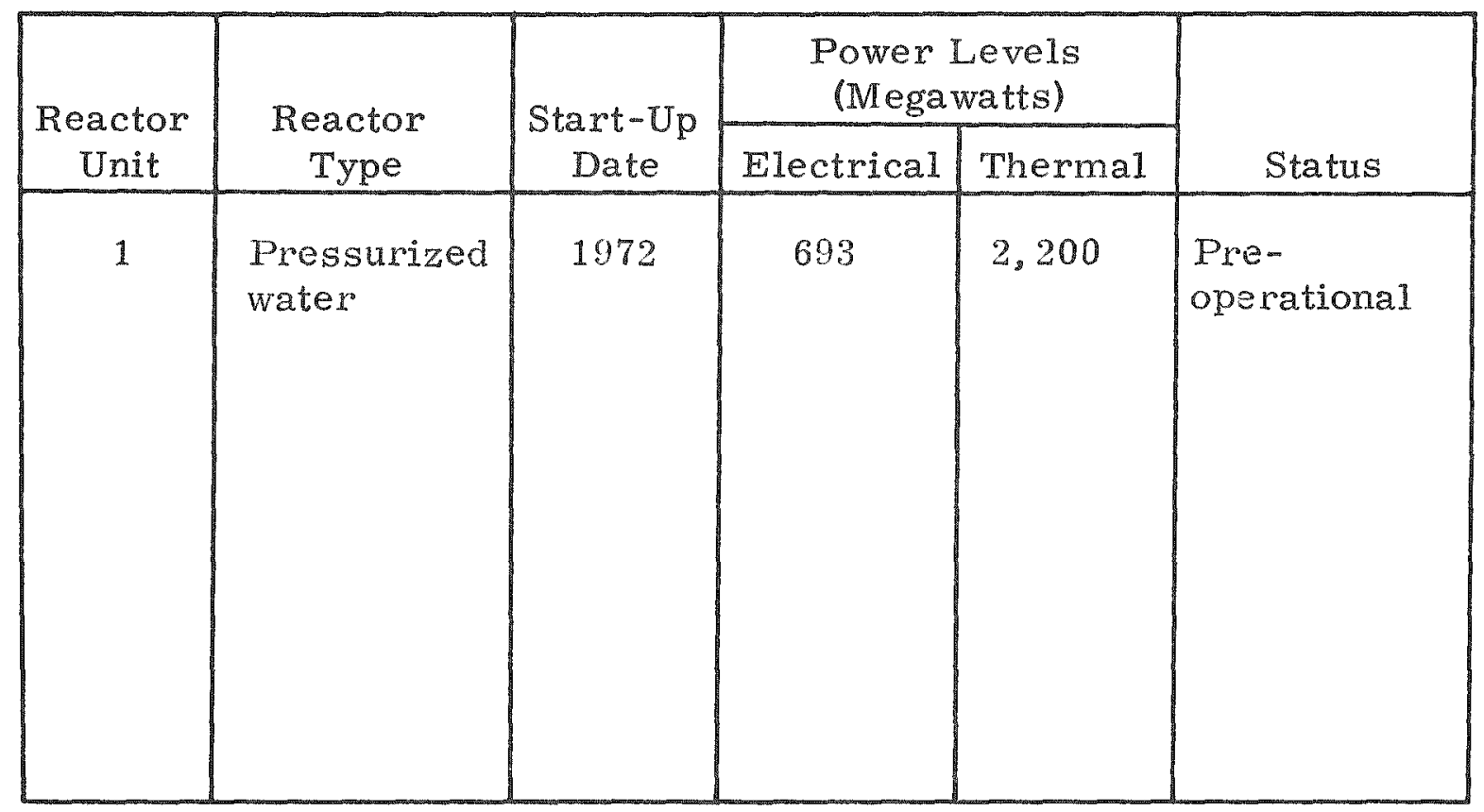


2.2

Site Area Characteristics

The terrain in the survey area is mainly flat marsh land covered with low vegetation and water. The Atlantic coast forms the eastern boundary of the area.

Table 2 lists the towns in the survey area with significant populations, by distance and direction from the reactor site. 
TABLE 2. Principal population centers within the Turkey Point area.

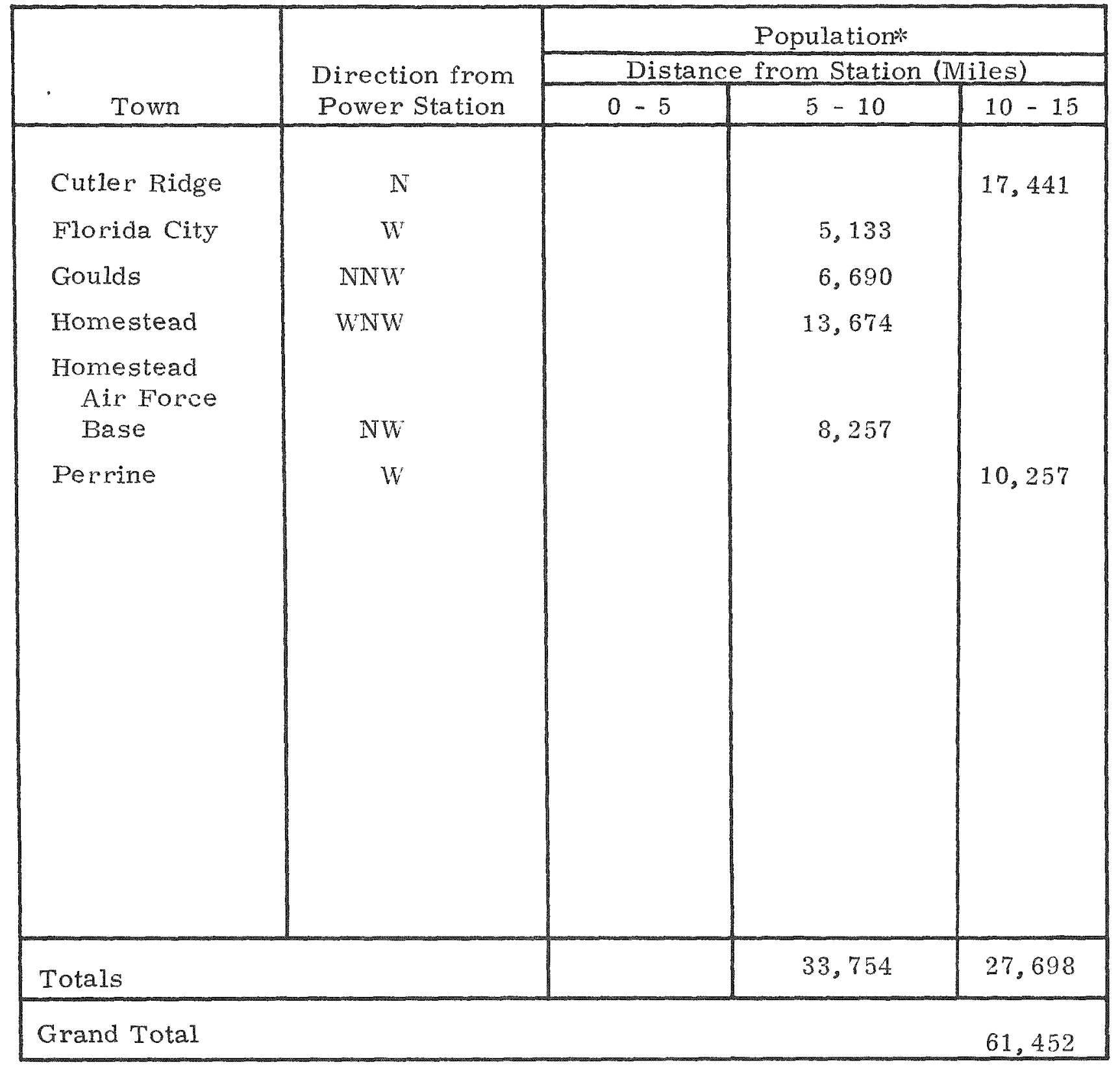

*1970 census figures (Ref. 2)。 


\section{SURVEY PIAN}

3.1

Specification of Flight Iines

The flight pattern for the Tuckey Point survey consisted of 12 flight lines approximately 12 nautical miles long and spaced one nautical mile apart. The lines were oriented in an east-west direction. Radiation data togethe $r$ with aircraft position and meteorological information were collected along each flight line. The survey area was restricted because of the proximity of Homestead Air Force Base.

3.2

Coordination with Local Aushorities

ARMS survey missions are conducted under special waiver from the Federal Aviation Administration. The survey plan was discussed with the appropriate General Aviation District Office, and publich announcements were published in the local newspapers prior to the survey operation in accordance with the FAA waiver for low-level flights.

The base of operations for the survey mission was Fort Lauderdale, Florida. 


\section{RADIOLOGICAI SURVLY}

4. 1 Survey Missions

The aerial survey of the Turkey Point Reactor area was conducted on 20 pril 1972. This survey required a total flying time of three hours.

Gamma gross-count and spectral data were simultaneously collected at an altitude of 500 feet. Spectra were accumulated over 1 -minute intervals during which the aircraft traveled approximately 12 miles; consequently, one spectrum per line was collected.

\subsection{Gross-Count Data}

As a first step in the analysis of the gross-count data, the background due to nonterrestrial radiation was subtracted. This background consists of cosmic-ray, aircraft, and airborne radioactivity contributions (Ref. 3). After correction for background, the data were normalized to a standard air mass. The resultant net-count data were then converted to exposure rate in microroentgens per hour ( $u R / h r)$ at the 3 -foot level above the ground. The cosmicray exposure rate was then added back to the terrestrial exposure rate. Finally, the composite exposure rate data, together with aircraft position incormation, were processed into an isoexposure contour map for overlay on U. S. Geological Survey topographic maps of the survey area.

An isoexposure map of the Turkey Point area is shown in Figure 2. The data shown on the map include a cosmic radiation contribution of $3.1 \mu R / h r$. Spatial resolution of the exposure rate data is determined by the field of view of the detector system, which is about $1 / 4$ mile. 


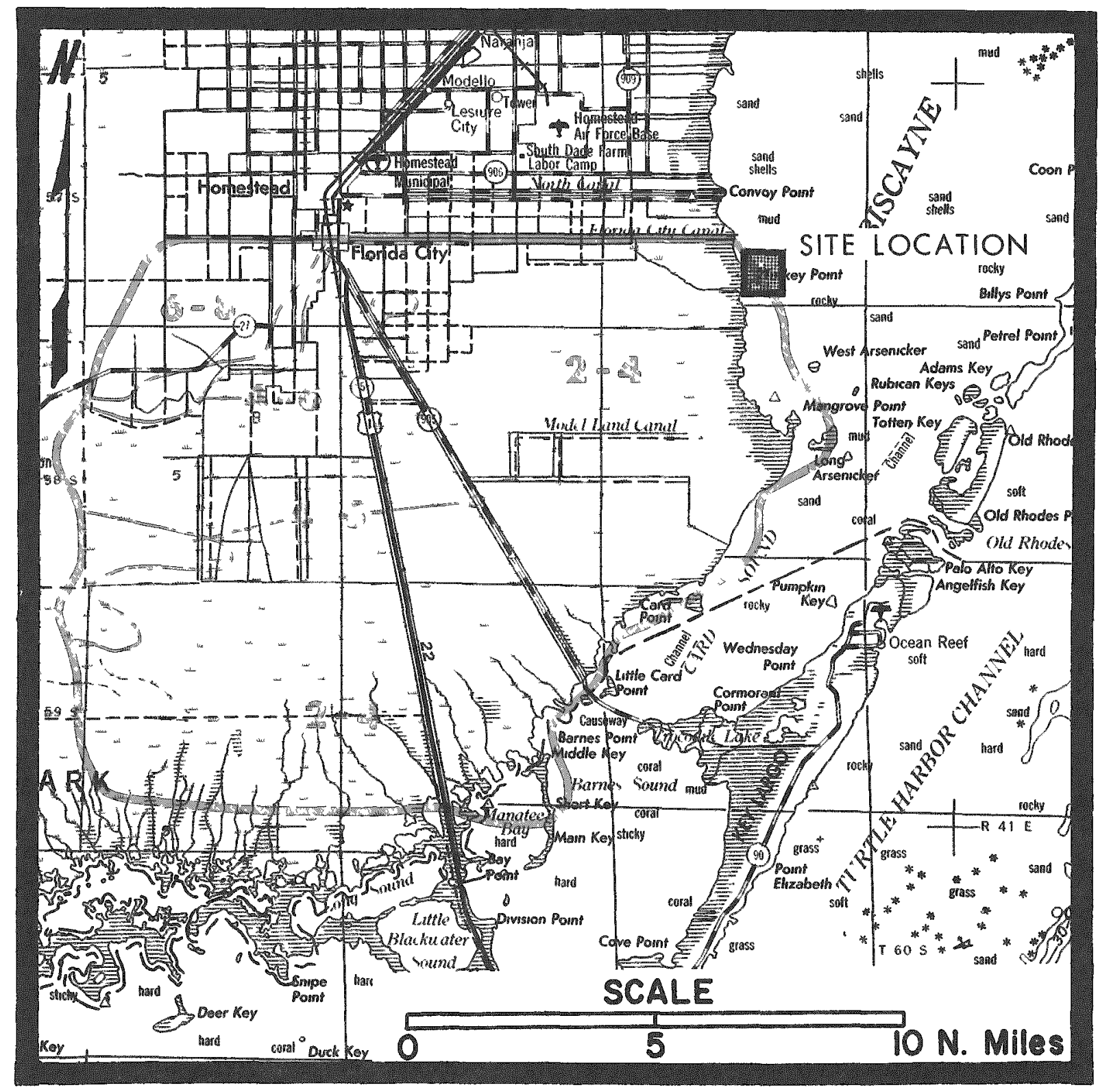

FIGURE 2. Gamma exposure rate contour map of the Turkey Point area, April 1972. (Values shown are in units of $u R / h r_{0}$ ) 
4. 3

Spectral Data

Spectral data were recorded from about 0.03 to 3.0 MeV. The recording system was calibrated prior to takeoff with an yitrium-88 source, which emits two prominent gamma-rays of 0.898 and 1.836 MeV. The gain for each crystal in the 14-crystal detector array was set independently.

A spectrum typical of those taken during the survey is shown in Figure 3 . Table 3 lists the prominent gamma-ray energies and associated source isotopes identified in the spectrum. Differences in shape between spectra taken over different portions of the survey area are minor, and the isotopes identified in all spectra are the same. Only isotopes consistent with normal background radiation are apparent. 


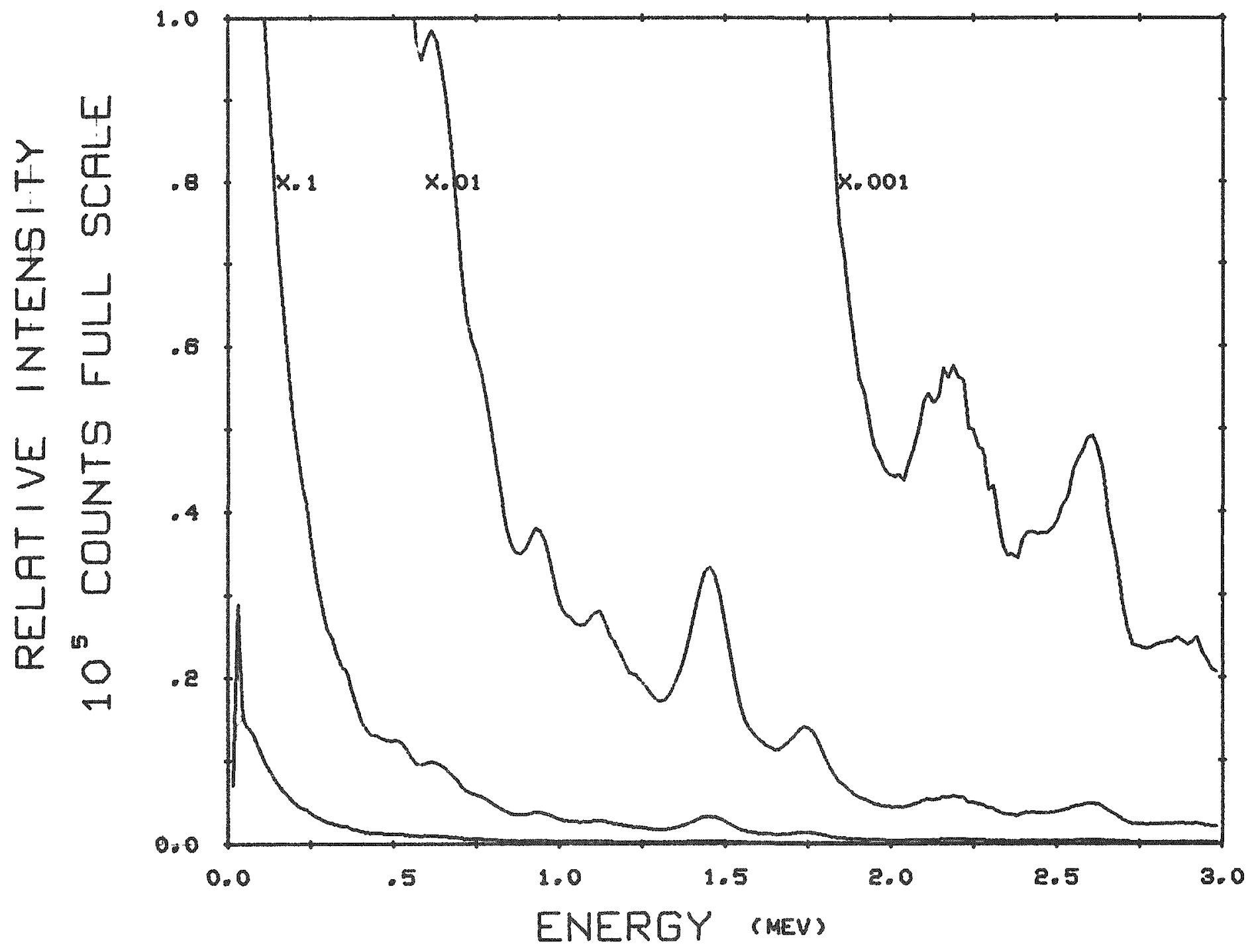

FIGURE 3. Typical gamma pulse height spectrum for survey area. 
TABLE 3. Gamma-ray energies and isotopes consistent with spectral data of Figure 3 .

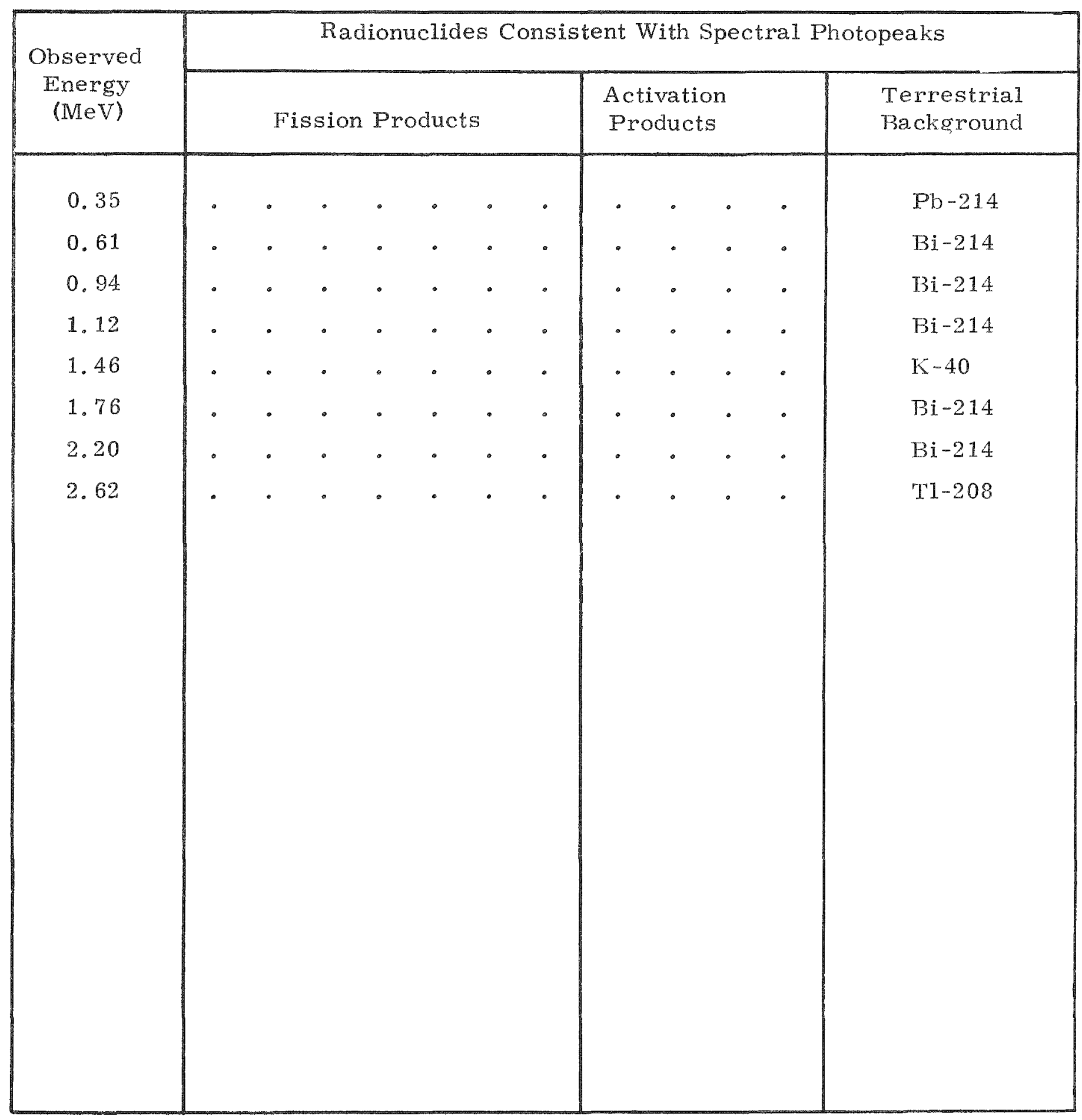




\section{SUMMARY AND CONCLUSTONS}

Since at the time of the survey the Turkey Point reactor had not yet commenzed oparating, the survey provided a background gamma radiation map of the reactor area. Exposure rates and radioactive isotopes revealed in the survey are consistent with normal terrestrial background.

The 3-loot level exposure rates mapped during the survey were mostly in the 2 to $6 \mathrm{uR} / \mathrm{hr}$ range. 


\section{REFTRENCES}

1. "Aerial Radiological Measuring Systems (ARMS) - Systems and Procedures Employed Through FY71, "AEC Report No. ARMS-71.6, in preparation.

2. 1970 Census of Population, Advance Report PC(VI)-11. U. S. Dept. of Commerce, Bureau of Census, December 1970 .

3. Burson, Z, G., Boyns. P. K., and Fritzsche, A. E., "Technical Procedures for Characterizing the Terrestrial Gamma Radiation Invironment by Aerial Surveys, "EG\&G/ LVAO Report No. 1183-1559, 1972. 